\title{
Position Statement on Opioid Analgesics in Pain Management - 2015 Update
}

The Canadian Pain Society is a chapter of the International

1 Association for the Study of Pain and supports the Declaration of Montreal (www.iasp-pain.org/DeclarationofMontreal).

This declaration recognizes the intrinsic dignity of all persons and states that withholding of pain treatment is profoundly wrong, leading to unnecessary suffering which is harmful and further recognizes the right of all people to have access to pain management without discrimination.

The Canadian Pain Society:

1. Recognizes that essential tools for managing moderate to severe pain comprise pharmacotherapy, which may include opioids among other analgesics, in combination with physical and psychological approaches.

2. Emphasizes that a strategy aiming to prevent diversion or misuse of opioid analgesics is essential, but must contain measures to assure that they remain available to those patients for whom they are required.

3. Encourages better education for health professionals and patients about the appropriate and safe use of opioid analgesics for the treatment of pain, based on the best research evidence.

4. Endorses the Canadian Guideline for the safe and effective use of opioids for chronic non-cancer pain (http://nationalpaincentre. mcmaster.ca/opioid/). 


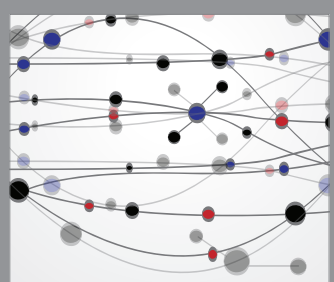

The Scientific World Journal
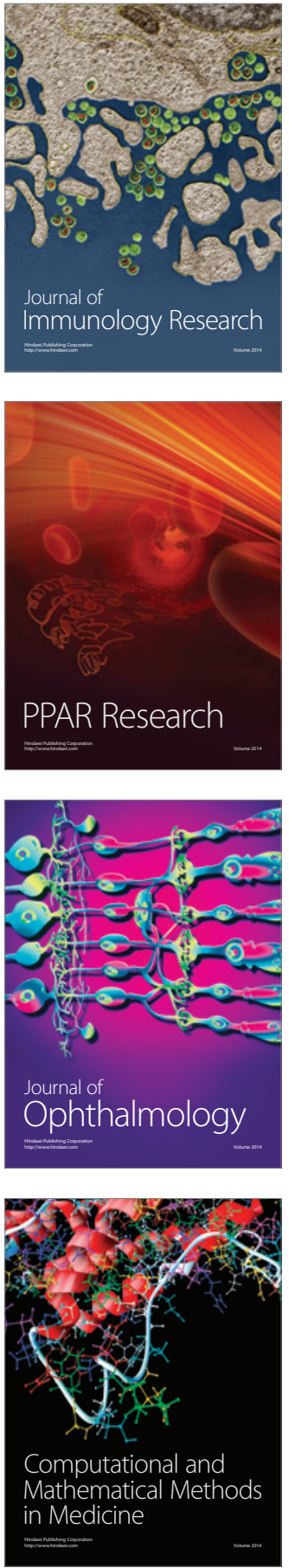

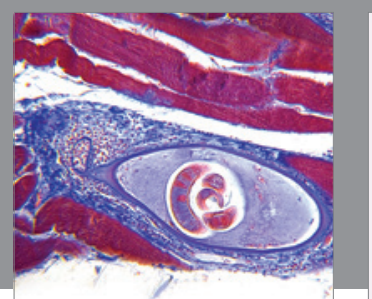

Gastroenterology Research and Practice

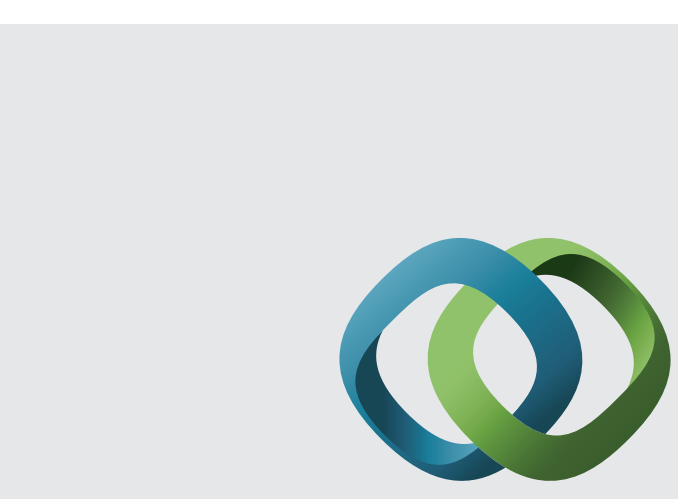

\section{Hindawi}

Submit your manuscripts at

http://www.hindawi.com
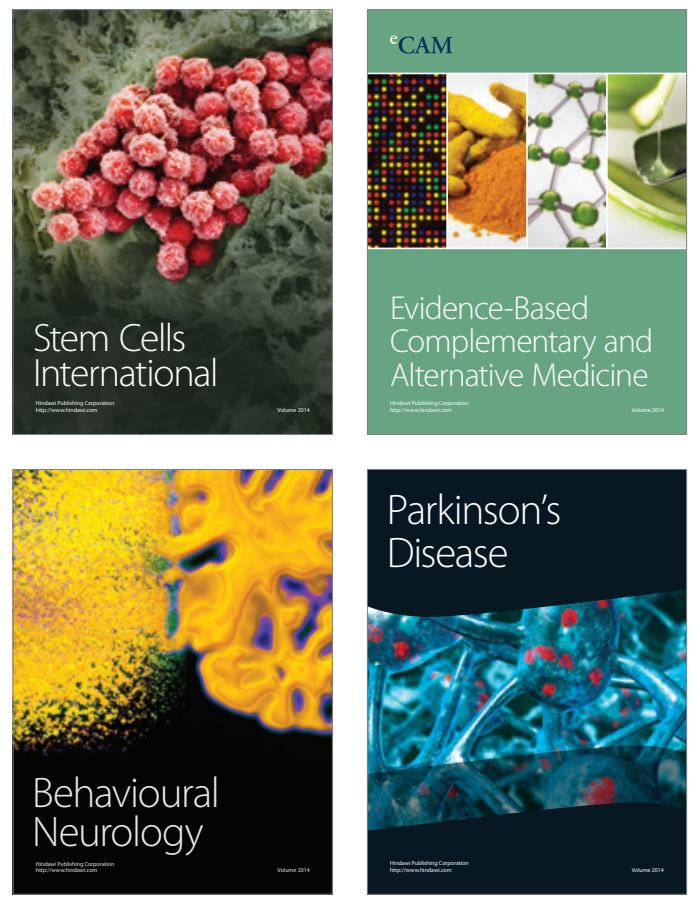
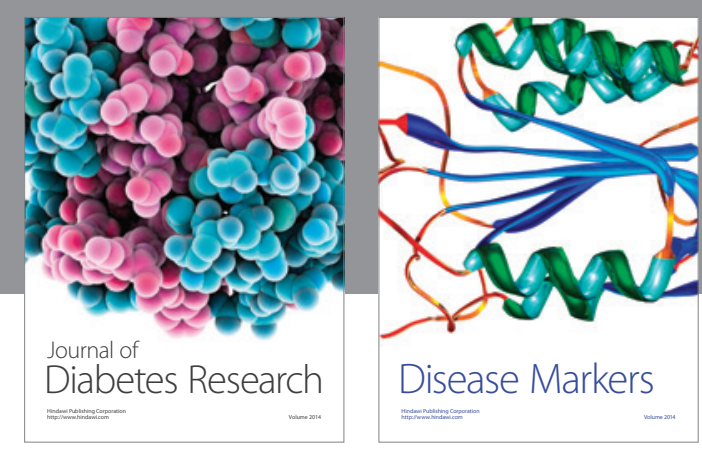

Disease Markers
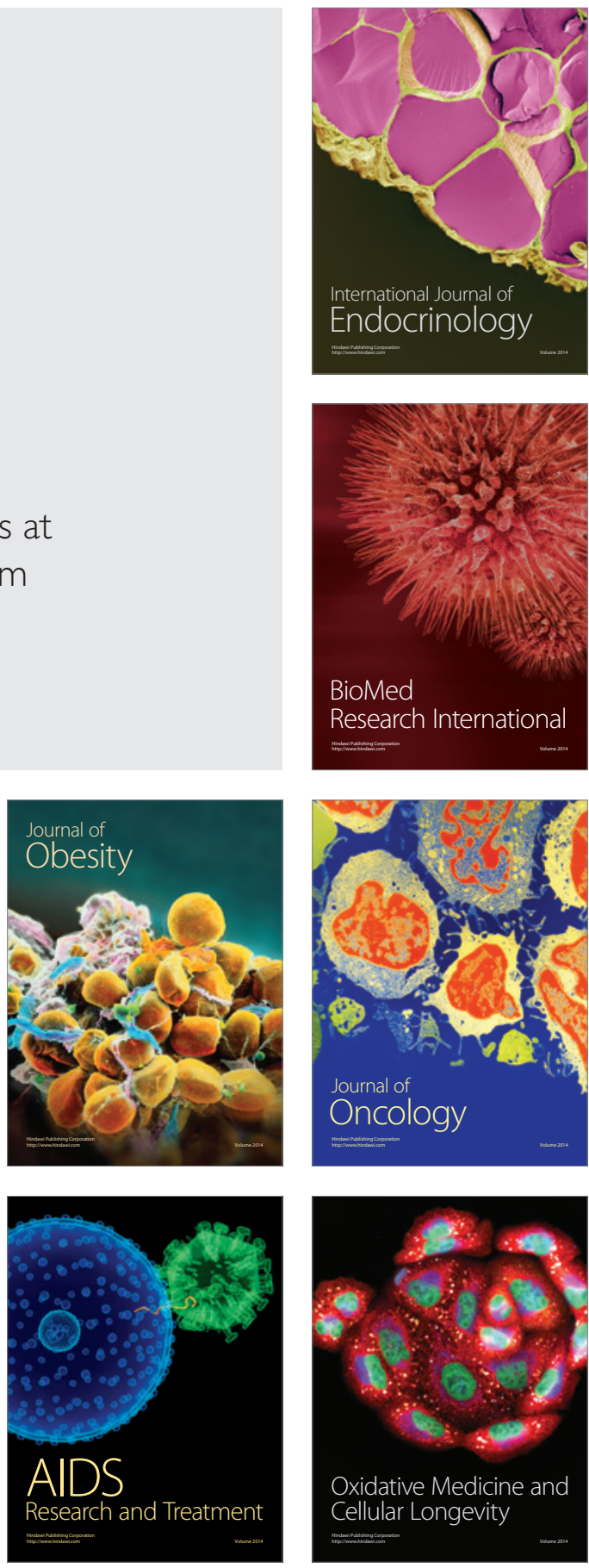